\title{
Effect of intravenous nitroglycerin on cerebral saturation in high-risk cardiac surgery
}

\section{[L'effet de la nitroglycérine intraveineuse sur la saturation cérébrale dans les}

chirurgies cardiaques à haut risque]

Dominique Piquette MD FRCPC, ${ }^{*} \|$ Alain Deschamps MD PhD FrCPC, ${ }^{*} \|$ Sylvain Bélisle MD FrCPC, ${ }^{*} \|$

Michel Pellerin MD FRCPS,$\dagger \|$ Sylvie Levesque MSc, $\mathfrak{S} \|$ Jean-Claude Tardif MD FRCPC, $\ddagger \|$

André Y. Denault MD FRCPC*\|

Purpose: To determine whether or not intravenous nitroglycerin (IV NTG) can prevent a decrease in near-infrared spectroscopy (NIRS) values during cardiopulmonary bypass (CPB).

Methods: We conducted a randomized double-blinded study in a tertiary academic center including 30 patients with a Parsonnet score $\geq 15$ scheduled for a high-risk cardiac surgery. The patients were randomized to receive either IV NTG (initial dose of $0.05 \mu \mathrm{g} \cdot \mathrm{kg}^{-1} \cdot \mathrm{min}^{-1}$, followed by $0.1 \mu \mathrm{g} \cdot \mathrm{kg}^{-1} \cdot \mathrm{min}^{-1}$ ) or placebo after anesthetic induction until the end of CPB. The primary outcome was a decrease of $10 \%$ in NIRS values during CPB.

Results: Despite the absence of between-group difference in the mean cerebral oxygen saturation during $\mathrm{CPB}$, there was a significant decrease in NIRS values during CPB in the placebo group, whereas mean NIRS values were maintained in the IV NTG group (-16.7\% vs $2.3 \%$ in the NTG, $P=0.019)$. Major hemodynamic variables were similar at corresponding time periods in both groups, while patients in the IV NTG group had higher CK-MB values and experienced greater blood loss during the first $24 \mathrm{hr}$ postoperatively.

Conclusion: Intravenous nitroglycerin administration before and during CPB may prevent a decrease in NIRS values associated with $C P B$ in high-risk cardiac surgery. Further studies are warranted to determine the efficacy and the risks associated with IV NTG infusion for this indication during CPB in high-risk patients.

CAN J ANESTH 2007 / 54: 9 / pp 718-727
Objectif: Déterminer si la nitroglycérine intraveineuse (NTG IV) peut empêcher ou non une diminution des valeurs de la spectroscopie par infrarouge (NIRS) pendant la circulation extracorporelle (CEC).

Méthode: Nous avons mené une étude randomisée à double insu dans un centre universitaire tertiaire incluant 30 patients présentant un score de Parsonnet $\geq 15$ et devant subir une chirurgie cardiaque à haut risque. Les patients ont été randomisés en deux groupes : NTG IV (dose initiale de $0,05 \mu \mathrm{g} \cdot \mathrm{kg}^{-1} \cdot \mathrm{min}^{-1}$, suivie de $0, I \mu \mathrm{g} \cdot \mathrm{kg}^{-1} \cdot \mathrm{min}^{-1}$ ), ou placebo après l'induction de l'anesthésie et jusqu'à la fin de la CEC. Le résultat primaire a été une diminution de $10 \%$ des valeurs de NIRS pendant la CEC.

Résultats: Malgré l'absence de différence inter-groupe dans la saturation d'oxygène cérébrale moyenne durant la CEC, une diminution significative des valeurs de NIRS pendant la CEC a été observée dans le groupe placebo, alors que les valeurs moyennes de NIRS se sont maintenues dans le groupe NTG IV (-16,7 \% vs 2,3\% dans le groupe NTG, $P=0,019$ ). Les variables hémodynamiques principales ont été semblables pour des périodes temporelles correspondantes dans les deux groupes, bien que les patients du groupe NTG IV aient présenté des valeurs CK-MB plus élevées et perdu davantage de sang durant les premières $24 \mathrm{~h}$ postopératoires.

Conclusion : L'administration de nitroglycérine intraveineuse avant et pendant la CEC pourrait empêcher une diminution des valeurs de NIRS associées à la CEC dans les chirurgies cardiaques à haut risque. Des études supplémentaires sont nécessaires afin de déterminer l'efficacité et les risques associés à une infusion NTG IV pour cette indication pendant la CEC chez des patients à haut risque.

From the Departments of Anesthesiology, ${ }^{*}$ Surgery, $†$ Medicine, $\ddagger$ Biostatistics, $\$ and the Research Center, $\|$ Montreal Heart Institute and Université de Montréal, Montréal, Québec, Canada.

Address correspondence to: Dr. André Y. Denault, Department of Anesthesiology and Research Center, Montreal Heart Institute and Université de Montréal, 5000 Bélanger Street, Montréal, Québec HIT 1C8, Canada. Phone: 514-376-3330, ext. 3732; Fax: 514-3768784; E-mail: denault@videotron.ca.

Supported by the Fonds de la recherche en santé du Québec, the Fondation de l'Institut de Cardiologie de Montréal, Montréal, QC; the Canadian Institutes of Health Research, Ottawa, ON, Canada. Presented at the Canadian Anesthesiologists' Society Meeting in Toronto,

June 2006. Dr. Tardif is the recipient of the Canadian Institutes of Health Research and Pfizer Chair in Atherosclerosis.

Conflicts of interest: None declared.

Accepted for publication February 12, 2007.

Revision accepted May 31, 2007.

Final revision accepted June 22, 2007.

CAN J ANESTH 54: 9 www.cja-jca.org September, 2007 


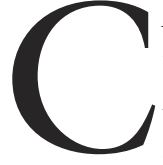

ARDIOPULMONARY bypass (CPB) is a major contributor to the inflammatory response observed after cardiac surgery $^{1}$ and to its clinical complications. ${ }^{2}$ Cardiopulmonary bypass is associated with complement activation, endotoxin liberation, and ischemiareperfusion episodes, leading to the activation of inflammatory cells ultimately responsible for tissue damage. ${ }^{3}$ Importantly, endothelial cell dysfunction precipitates a decrease in the production of endogenous nitric oxide (NO), compromising significantly both vascular tone and local tissue perfusion. ${ }^{4}$ However, endothelial cells maintain their sensitivity to exogenous $\mathrm{NO}$ donors. ${ }^{5}$

Therefore, administration of intravenous nitroglycerin (IV NTG), a NO donor, has been proposed in a limited number of studies as a strategy to either prevent $^{6}$ or to correct ${ }^{7,8}$ peripheral tissue hypoperfusion during ischemic stress. Through $\mathrm{NO}$-induced vasodilatation, ${ }^{5}$ IV NTG could provide a mechanism of protection against ischemia-reperfusion injuries. In animals, IV NTG helps to maintain structural and functional integrity of tissues at risk. ${ }^{9-11}$ Intravenous nitroglycerin also reproduces the effects of endogenous late pre-conditioning, ${ }^{12}$ a natural mechanism that increases the resistance of hypoperfused tissues to subsequent ischemic episodes. The clinical impact of these effects in humans is still largely unknown.

Currently, the intraoperative measurement of endothelial function and local tissue perfusion is technically challenging. Near-infrared spectroscopy (NIRS) has been advocated as a useful continuous monitor of cerebral oxygen saturation that provides an indicator of the adequacy of cerebral oxygen delivery during cardiac surgery. ${ }^{13}$ Near-infrared spectroscopy has been used mainly to detect and correct intraoperative cerebral desaturations, even if the prognostic value of these desaturations, the specific tresholds requiring intervention, and the clinical impact of this type of monitoring are still debated. ${ }^{14}$ Near-infrared spectroscopy provides a non-invasive measure of local tissue perfusion that can be used during non pulsative flow conditions of $\mathrm{CPB}$. This monitoring has been associated recently with a decrease in major organ dysfunction after cardiac surgery, ${ }^{15}$ providing a rationale for its use.

Because the benefits of IV NTG in maintaining tissue perfusion during cardiac surgery remain unclear, we conducted a double-blinded randomized controlled trial to evaluate the effect of IV NTG on NIRS values during CPB in high-risk cardiac surgery patients. We hypothesized that infusion of NTG infusion initiated prior to $\mathrm{CPB}$ would be superior to placebo in maintaining cerebral oxygen saturation, as an index of tissue perfusion, during high-risk cardiac surgery.

\section{Methods}

\section{Study population}

Following approval by the Ethics and Research Committee and after obtaining written informed consent, 30 patients undergoing elective cardiac surgery at the Montreal Heart Institute, a tertiary care university hospital, were recruited between March and November 2004. Eligible patients were those undergoing a cardiac surgical procedure requiring $\mathrm{CPB}$ who were considered at high-risk for postoperative morbidity and mortality, as defined by a Parsonnet score $\geq$ 15. ${ }^{16}$ Patients were excluded if they had received IV NTG for more than $12 \mathrm{hr}$ within $24 \mathrm{hr}$ of surgery.

\section{Treatment protocol}

All patients were premedicated with morphine 0.1 $\mathrm{mg} \cdot \mathrm{kg}^{-1}$ im and midazolam 3-8 $\mathrm{mg}$ im administered approximately one hour before surgery. In the operating room, standard monitoring was applied including five-lead electrocardiogram, digital pulse oximeter, capnography, radial arterial line, a $15-\mathrm{cm}$ triple-lumen catheter (CS-12703, Arrow International Inc., Reading, CA, USA) and a pulmonary artery catheter (Swan-Ganz Thermodilution catheter 7.5 Fr; Baxter Healthcare Corporation, Irvine, CA, USA). Regional cerebral oxygen saturation was monitored using NIRS.

Near-infrared spectroscopy technology is based on the principle that each substance has a characteristic absorbance. In the near-infrared wavelengths, hemoglobin and cytochrome c-oxidase, also known as the enzyme cytochrome aa3, are the main chromophores (light absorbing substance at a specific frequency). The light source of the oximeter provides two continuous wavelengths of near-infrared light (730 and 810 $\mathrm{nm}$ ) on the forehead, at the area corresponding to the junction between the anterior and middle cerebral arteries. Two detectors, respectively having a sourcedetector spacing of 3 and $4 \mathrm{~cm}$, are also present to distinguish the extra-cerebral from the intra-cerebral tissue signal. The ratio of oxygenated hemoglobin and total hemoglobin is measured and a subtraction of the superficial signal from the deeper signal is made by the monitor to obtain the regional hemoglobin oxygen saturation in the frontal cortex. For this reason, it is assumed that extra-cerebral tissue has a minor contribution to this value. ${ }^{13}$ The venous blood contribution to cerebral oximetry value is about $75 \%$, similar in normoxic, hypoxic and hypocapnic conditions, ${ }^{13}$ thus 


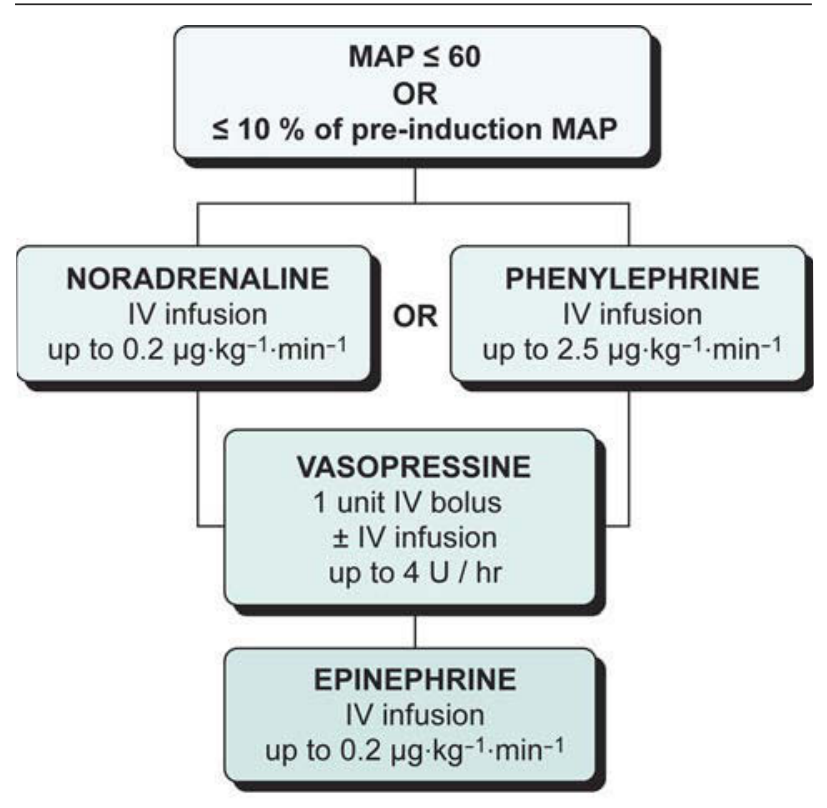

FIGURE 1 Use of vasopressors before and during CPB. $\mathrm{CPB}=$ cardiopulmonary bypass; $\mathrm{MAP}=$ mean arterial pres sure; $\mathrm{IV}=$ intravenous; $\mathrm{NS}=$ normal saline.

resulting in an evaluation of the balance between oxygen delivery and consumption. For the purpose of this study, we used the INVOS 4100 (Somanetics, Troy, MI, USA) according to the manufacturer's instructions, in all patients.

Anesthesia was induced with standardized doses of midazolam $0.04 \mathrm{mg} \cdot \mathrm{kg}^{-1} i v$, sufentanil $\mathrm{l} \mu \mathrm{g} \cdot \mathrm{kg}^{-1}$ $i v$, while neuromuscular blockade was achieved with rocuronium $0.6 \mathrm{mg} \cdot \mathrm{kg}^{-1} i v$. Anesthesia was maintained with sufentanil $\mathrm{l} \mu \mathrm{g} \cdot \mathrm{kg}^{-1} \cdot \mathrm{hr}^{-1}$, midazolam $0.04 \mathrm{mg} \cdot \mathrm{kg}^{-1} \cdot \mathrm{hr}^{-1}$. propofol $30-50 \mu \mathrm{g} \cdot \mathrm{kg}^{-1} \cdot \mathrm{min}^{-1}$ and isoflurane. All patients were ventilated with $100 \%$ oxygen and minute ventilation was adjusted to maintain $\mathrm{PaCO}_{2} 40 \pm 5 \mathrm{mmHg}$ confirmed by serial arterial blood gas analysis. Intravenous fluids $(0.9 \%$ normal saline) were administered according to estimated insensible losses of $7 \mathrm{~mL} \cdot \mathrm{kg}^{-1} \cdot \mathrm{hr}^{-1}$ during the surgery and titrated according to the blood pressure and the central venous pressure. A decrease in the mean arterial blood pressure below 60 was treated with fluid administration in presence of a low central venous pressure, or by the use of vasopressors according to a predetermined protocol (Figures 1 and 2). In case of low cardiac output, milrinone was administered at the anesthesiologists' discretion. Cardiopulmonary bypass was instituted and maintained according to a strict

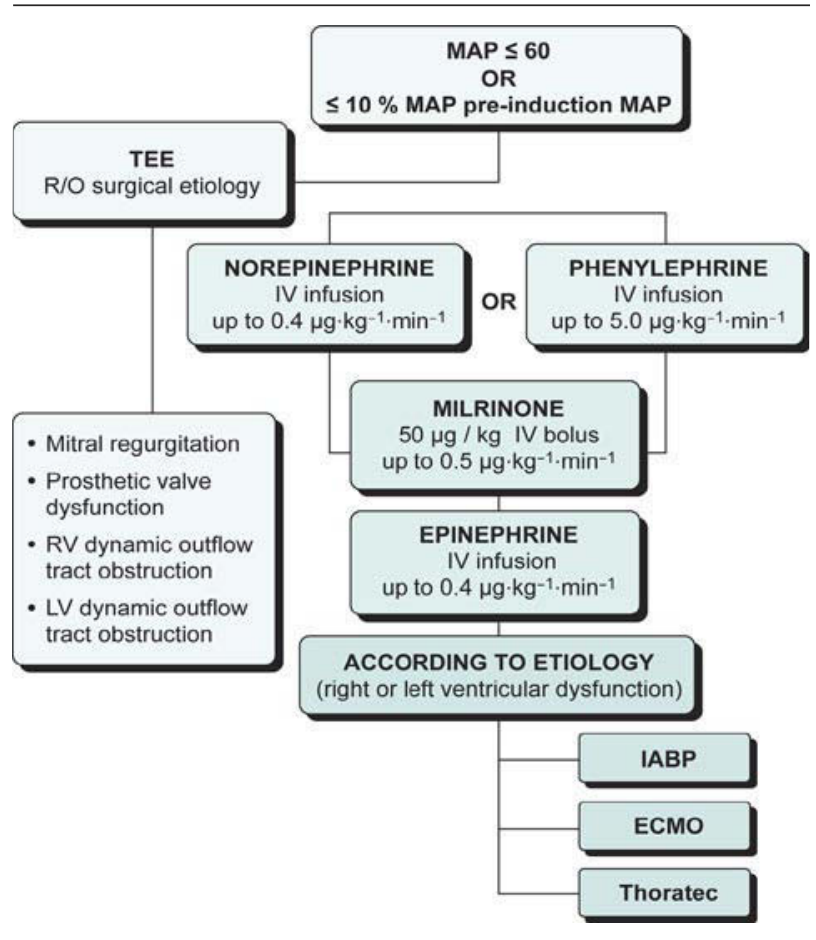

FIGURE 2 Use of vasopressors at the end of CPB. CPB = cardiopulmonary bypass MAP = mean arterial pressure; $\mathrm{TEE}=$ transesophegeal echocardiography; IV = intravenous; $\mathrm{NS}=$ normal saline; $\mathrm{RV}=$ right ventricle; $\mathrm{LV}=$ left ventricle; IABP = intra-aortic balloon pump; ECMO = extracorporeal membrane oxygenation. ${ }^{*}$ The mean arterial pressure value confirmed with central aortic measurement.

protocol with standardized canulation sites, pump flow, blood gas management, and mean arterial pressure and temperature targets. Blood cardioplegia was used in all patients. Induction and maintenance cardioplegic solutions were cold to tepid $\left(15\right.$ to $\left.29^{\circ} \mathrm{C}\right)$. The blood to crystalloid ratio was $4: 1$. The pump flow was adjusted to obtain an adjusted output of $2.2 \mathrm{~L} \cdot \mathrm{m}^{-}$ 2 of body surface area. The pump flow was reduced to $0.5 \mathrm{~L} \cdot \mathrm{min}^{-1}$ for aortic clamping and unclamping. The pumps for all patients were SIII (Stockert, Munchen, Germany) roller pumps. Oxygenators were Sorin Monolyth (Mirandola, MO, Italy). For coronary artery bypass procedures, temperature was allowed to drift to $34^{\circ} \mathrm{C}$. Valve and complex procedures were done with core temperatures between $32-34^{\circ} \mathrm{C}$. Aortic procedures with circulatory arrest were done at $15-18^{\circ} \mathrm{C}$. Selective antegrade and retrograde cerebral perfusion were used on a case-by-case basis. Weaning 
from $\mathrm{CPB}$ was attempted after systemic temperature (central and vesical) was $>36^{\circ} \mathrm{C}$. An intravenous bolus of aprotinin (2 MU) followed by an infusion (500 $000 \mathrm{U} \cdot \mathrm{hr}^{-1}$ ) was administered during CPB.

\section{Nitroglycerin administration protocol}

Patient randomization was achieved using a computer-generated table of random numbers done by the Biostatistical Department of our institution. The allocation sequence was transmitted directly to the hospital pharmacist the day before the surgery - the investigator had no access to the randomization sequence. The study drug was prepared by the pharmacist and delivered to the operating room wrapped in an opaque covering to maintain blinding. Following induction of anesthesia, administration of NTG $\left(0.1 \mathrm{mg} \cdot \mathrm{mL}^{-1}\right.$; Sabex, Boucherville, QC, Canada) or placebo (D5 $\%, \mathrm{~mL} \cdot \mathrm{min}^{-1}$ equivalent to the NTG infusion), began at a rate of $0.5 \mu \mathrm{g} \cdot \mathrm{kg}^{-1} \cdot \mathrm{min}^{-1}$, and was increased to $\mathrm{l}$ $\mu \mathrm{g} \cdot \mathrm{kg}^{-1} \cdot \mathrm{min}^{-1}$ immediately after initiation of CPB. At the end of the $\mathrm{CPB}$, the study drug was stopped and the anesthesiologist was then free to use any medication (including IV NTG) required for hemodynamic stabilization of the patient (Figures 1 and 2). In the presence of refractory hypotension (mean arterial pressure $<60 \mathrm{mmHg}$ persisting $>$ five minutes), the study drug was discontinued at any time during the surgery.

\section{Data collection}

At the time of randomization, demographic, diagnostic class (New York Heart Association (NYHA) class, Parsonnet score, comorbidities, ejection fraction), and therapeutic (medication, type of surgery, redo) information was obtained for every patient.

After induction of anesthesia and before beginning the study drug infusion (time 0), baseline hemodynamic values were measured along with arterial and mixed venous blood gas determinations. The same variables were recorded just before (time 1 ) and immediately after (time 2) CPB.

Cerebral oxygen saturations were measured continuously and recorded every $30 \mathrm{sec}$ from the time of anesthetic induction to closure of the thorax. The CPB duration, aortic cross-clamping time, total intravenous fluids administered, total diuresis, total dose of heparin, and total dose and duration of each vasopressor were recorded.

\section{Outcome measures}

The primary outcome was the between-group difference in the mean hemispheric cerebral oxygen saturation during $\mathrm{CPB}$. Secondary outcomes included serial measures of cerebral oxygen saturation at specific times; the number of episodes ( $\geq$ one minute) with a relative decrease of $\geq 20 \%$ from the baseline of the cerebral saturation and the proportion of time during $\mathrm{CPB}$ with a cerebral saturation below that threshold; other markers of tissue perfusion included whole blood lactate concentration, arteriovenous difference of partial $\mathrm{CO}_{2}$ pressure, and mixed venous oxygen saturation from time 0 to time 2 ; difficult separation from $\mathrm{CPB}$, defined as systolic arterial blood pressure $<80 \mathrm{mmHg}$ with a diastolic pulmonary artery pressure or a wedge pressure $>15 \mathrm{mmHg}$ and use of vasopressors (norepinephrine $>0.06 \mu \mathrm{g} \cdot \mathrm{kg}^{-1} \cdot \mathrm{min}^{-1}$, epinephrine $>0.06 \mu \mathrm{g} \cdot \mathrm{kg}^{-1} \cdot \mathrm{min}^{-1}$, dobutamine $>$ $2 \mu \mathrm{g} \cdot \mathrm{kg}^{-1} \cdot \mathrm{min}^{-1}$ ), or use of intravenous milrinone during withdrawal of $\mathrm{CPB}$ or transport to the intensive care unit (ICU). Other outcomes included CK-MB, new use of an intra-aortic balloon pump during surgery, successful cardiopulmonary resuscitation during hospital stay, length of ICU and total hospital stay, and death. Safety outcome variables included blood loss during and $24 \mathrm{hr}$ after surgery, anemia during surgery, need for transfusion, and ratio of the partial pressure of oxygen in arterial blood to inspired $\mathrm{O}_{2}$ fraction $\left(\mathrm{PaO}_{2} / \mathrm{FIO}_{2}\right.$ ratio). Follow-up ended when the patient was discharged from hospital.

\section{Statistical analysis}

On the assumption of a baseline cerebral hemispheric saturation $( \pm$ SD $)$ of $65 \%( \pm 9),{ }^{\mathrm{A}}$ we required that the planned sample size that would provide an $80 \%$ chance of detecting a difference of $10 \%$ in the mean cerebral saturation level during the $\mathrm{CPB}$ at a significance level of 0.05 . This generated an estimate of 15 patients per group. In the absence of any previous study aimed at preventing cerebral desaturations during cardiac surgery (all previous studies corrected the desaturations), a $10 \%$ absolute difference in the mean cerebral saturation was selected as a minimal clinically important difference. This choice was based on a previous study showing a reduction in mortality of septic patients by the maintenance of a central venous saturation $>70 \%$. The difference in the mean venous oxygen saturation between the treatment and placebo groups during this study was $10 \%$. Although NIRS and central venous catheter measures are not equivalent, we aimed to detect a similar difference in the absence of more relevant data, and because our study

A Edmonds HL Jr. Detection and treatment of cerebral hypoxia key to avoiding intraoperative brain injuries. APSF Newsletter 1999; 14: 25-32. 
TABLE I Baseline characteristics of the study population

\begin{tabular}{|c|c|c|}
\hline Characteristic & $\begin{array}{l}\text { Control } \\
(n=15)\end{array}$ & $\begin{array}{l}\text { Nitroglycerin } \\
(n=15)\end{array}$ \\
\hline Age (yr) & $74 \pm 9$ & $71 \pm 10$ \\
\hline \multicolumn{3}{|l|}{$\operatorname{Sex}, n(\%)$} \\
\hline Male & $6(40)$ & $9(60)$ \\
\hline Female & $9(60)$ & $6(40)$ \\
\hline BMI $\left(\mathrm{kg} \cdot \mathrm{m}^{-2}\right)$ & $27 \pm 4$ & $26 \pm 4$ \\
\hline \multicolumn{3}{|l|}{ NYHA class, $n(\%) *$} \\
\hline 1 & $5(36)$ & $2(15)$ \\
\hline 2 & $3(21)$ & $3(23)$ \\
\hline 3 & $5(36)$ & $5(39)$ \\
\hline 4 & $1(7)$ & $3(23)$ \\
\hline Parsonnet score & $25 \pm 8$ & $29 \pm 9$ \\
\hline Current smoking, $n(\%)$ & $2(13)$ & $1(7)$ \\
\hline \multicolumn{3}{|l|}{ Type of surgery, $n(\%)$} \\
\hline One valve & $4(27)$ & $4(27)$ \\
\hline Multiple valves & $1(7)$ & $1(7)$ \\
\hline $\mathrm{CABG}$ & $3(20)$ & $2(13)$ \\
\hline CABG + valve (s) & $7(47)$ & $7(47)$ \\
\hline Other & $0(0)$ & $1(7)$ \\
\hline \multicolumn{3}{|l|}{ Cardiac disease, $n(\%)$} \\
\hline Prior myocardial infarction & $3(20)$ & $2(13)$ \\
\hline Recent myocardial infarction & $3(20)$ & $3(20)$ \\
\hline Unstable angina & $4(27)$ & $4(27)$ \\
\hline Congestive heart failure & $9(60)$ & $11(73)$ \\
\hline Acute endocarditis & $0(0)$ & $2(13)$ \\
\hline Atrial fibrillation & $6(40)$ & $5(33)$ \\
\hline Pacemaker & $1(7)$ & $1(7)$ \\
\hline \multicolumn{3}{|l|}{ Co-morbidities, $n(\%)$} \\
\hline Hypertension & $11(73)$ & $9(60)$ \\
\hline Diabetes mellitus & $2(13)$ & $3(20)$ \\
\hline Peripheral vascular disease & $6(40)$ & $5(33)$ \\
\hline Renal failure & $5(33)$ & $6(40)$ \\
\hline COPD & $4(27)$ & $1(7)$ \\
\hline \multicolumn{3}{|l|}{ Drug therapy at admission, $n$ (\%) } \\
\hline Nitrates & $4(27)$ & $3(20)$ \\
\hline Calcium-channel antagonists & $6(40)$ & $4(27)$ \\
\hline Beta-blockers & $7(47)$ & $13(87)$ \\
\hline ACE inhibitors & $8(53)$ & $8(53)$ \\
\hline Digoxin & $5(33)$ & $3(20)$ \\
\hline Diuretics & $9(60)$ & $12(80)$ \\
\hline Salicylates & $5(33)$ & $5(33)$ \\
\hline Left ventricular ejection fraction (\%) & $49 \pm 12$ & $50 \pm 12$ \\
\hline $\begin{array}{l}\text { Glycemia at the beginning of } \\
\text { surgery }\left(\mathrm{mmol} \cdot \mathrm{L}^{-1}\right)\end{array}$ & $6.4 \pm 1.7$ & $6.9 \pm 2.1$ \\
\hline \multicolumn{3}{|l|}{ Duration of surgery (min) } \\
\hline $\mathrm{CPB}$ & $97 \pm 32$ & $118 \pm 49$ \\
\hline Aorta clamping & $72 \pm 28$ & $84 \pm 49$ \\
\hline
\end{tabular}

was based on the same concept of using saturation values as a marker of the adequacy of tissue perfusion. Results are expressed as mean \pm SD deviation or with median (min, max) according to the distribution for continuous variables, or as number and percentages for categorical variables. A logarithmic transformation was used when a continuous variable was not normally distributed. For continuous variables, comparison of groups was performed using the parametric ( $t$ test) or nonparametric (Wilcoxon) test depending on the distribution. For categorical variables, comparison of groups was performed using the Pearson Chi-square test.

To test variation between groups and over time of hemodynamic values, blood gas and cerebral saturation results, repeated measures ANOVA with GROUP, TIME (T0, T1 and T2) and GROUP $\times$ TIME interaction were performed. In presence of a significant GROUP $\times$ TIME interaction, comparisons of TIME for each group were performed. When there is no significant GROUP $\times$ TIME interaction and significant TIME effect, comparisons between TIME were performed. The same method was used for analysis of repeated hemispheric cerebral saturation measures. To further explore the changes in mean cerebral oxygenation during $\mathrm{CPB}$ between patients, the duration of $\mathrm{CPB}$ was standardized and the change in saturation in relation to the baseline value was plotted and analyzed using a repeated generalized estimated equation approach. Therefore, the baseline variation of mean cerebral oxygenation during $\mathrm{CPB}$ could be compared for every patient according to each group, placebo or NTG. Statistical analysis was done with computer software SAS version 8.02 (SAS Institute Inc., Cary, NC, USA). A $P$-value $<0.05$ was considered statistically significant.

\section{Results}

A total of 32 patients were randomized in the study. Two patients did not receive the study drug and were excluded because the scheduled anesthesiologist was changed. The data from 30 patients were analyzed. Their clinical and demographic characteristics are presented in Table I. Except for the use of preoperative beta-blockers on admission (control: $47 \%$ vs IV NTG: $87 \%$ ), other characteristics were similar between groups. No patient in the control group received IV NTG before the end of the CPB. Patients in the placebo and IV NTG groups received, respectively, 2.60 $\mathrm{mg}$ of the study drug before the $\mathrm{CPB}$, and $2.15 \mathrm{mg}$ of an equivalent volume of dextrose for the placebo group. During CPB, patients received $8.84 \mathrm{mg}$ of the study drug and $6.75 \mathrm{mg}$ of an equivalent volume of dextrose, respectively. From the end of $\mathrm{CPB}$ to the time of chest closure, when NTG could be given as result of hemodynamic profiles, patients in the control and the NTG groups received $0.65 \pm 1.68 \mathrm{mg}$ and $0.55 \pm 1.03 \mathrm{mg}(P=0.55)$ of IV NTG, respectively. 
TABLE II Mean cerebral saturation and other perfusion values during surgery

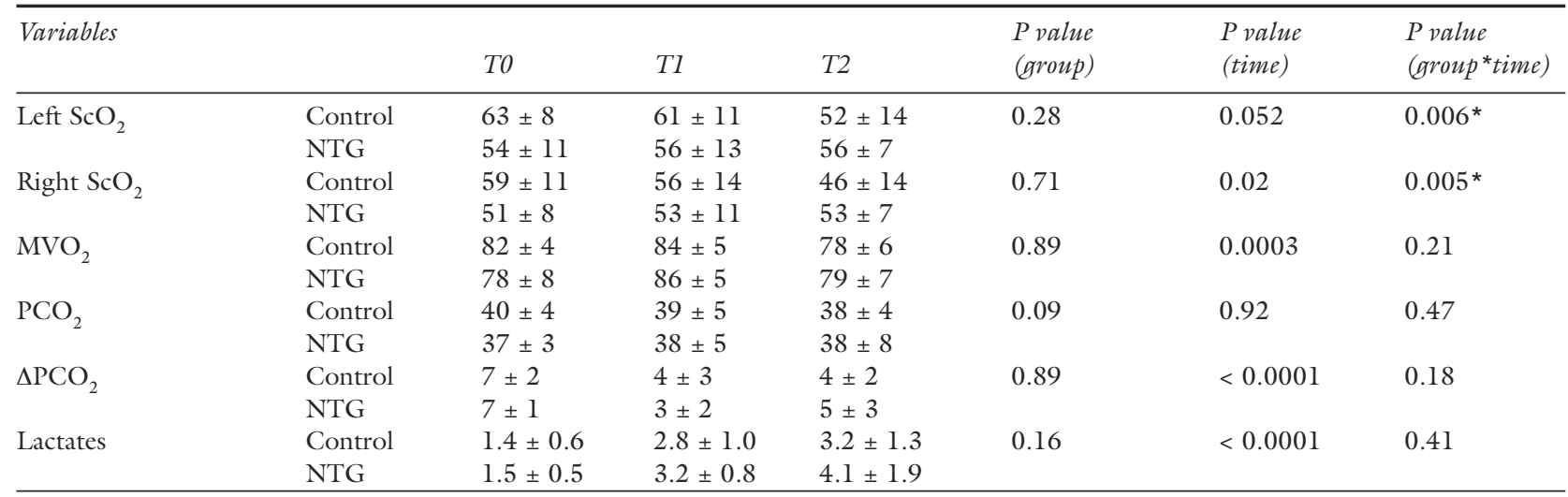

$\mathrm{ScO}_{2}=$ cerebral saturation; NTG = nitroglycerin; T0 = baseline value before nitroglycerin infusion; Tl = beginning of cardiopulmonary bypass; $\mathrm{T} 2$ = end of cardiopulmonary bypass times; $\mathrm{MVO}_{2}=$ mixed venous blood saturation provided by the distal port of the Swan-Ganz catheter; $\Delta \mathrm{PCO}_{2}=$ difference between partial pressure of carbon dioxide of arterial and venous blood. * T0 and Tl are statistically different from T2, but only in control group.

TABLE III Hemodynamic values during surgery

\begin{tabular}{|c|c|c|c|c|c|c|c|}
\hline \multicolumn{5}{|l|}{ Hemodynamic variables } & \multirow{3}{*}{$\begin{array}{l}\text { P value } \\
\text { (group) }\end{array}$} & \multirow{3}{*}{$\begin{array}{l}\begin{array}{l}\text { P value } \\
\text { (time) }\end{array} \\
0.053\end{array}$} & \multirow{3}{*}{$\begin{array}{l}\begin{array}{l}\text { P value } \\
\text { (group }^{*} \text { time) }\end{array} \\
0.95\end{array}$} \\
\hline Systolic BP (mmHg) & Control & $109 \pm 16$ & $101 \pm 15$ & $109 \pm 20$ & & & \\
\hline & NTG & $105 \pm 21$ & $95 \pm 17$ & $106 \pm 15$ & & & \\
\hline \multirow[t]{2}{*}{ Heart rate (beats. $\mathrm{min}^{-1}$ ) } & Control & $53 \pm 11$ & $59 \pm 11$ & $70 \pm 11$ & \multirow[t]{2}{*}{0.08} & \multirow[t]{2}{*}{$<0.0001^{*}$} & \multirow[t]{2}{*}{0.83} \\
\hline & NTG & $55 \pm 9$ & $61 \pm 15$ & $78 \pm 15$ & & & \\
\hline $\mathrm{RAP}(\mathrm{mmHg})$ & Control & $10 \pm 3$ & $10 \pm 5$ & $12 \pm 5$ & 0.03 & $0.01 *$ & 0.42 \\
\hline \multicolumn{8}{|l|}{ Systolic PAP (mmHg) } \\
\hline & Control & $32 \pm 6$ & $32 \pm 7$ & $37 \pm 8$ & \multirow[t]{2}{*}{0.004} & \multirow[t]{2}{*}{$0.0006^{*}$} & \multirow[t]{2}{*}{0.16} \\
\hline & NTG & $44 \pm 18$ & $37 \pm 10$ & $48 \pm 10$ & & & \\
\hline \multirow[t]{2}{*}{ PAWP (mmHg) } & Control & $15 \pm 4$ & $15 \pm 4$ & $20 \pm 4$ & \multirow[t]{2}{*}{0.35} & \multirow[t]{2}{*}{0.06} & \multirow[t]{2}{*}{0.77} \\
\hline & NTG & $18 \pm 7$ & $15 \pm 9$ & $22 \pm 3$ & & & \\
\hline \multirow{2}{*}{$\begin{array}{l}\text { Indexed cardiac output } \\
\left(\mathrm{L} \cdot \mathrm{min}^{-1} \cdot \mathrm{m}^{-2}\right)\end{array}$} & Control & $2.0 \pm 0.3$ & $1.9 \pm 0.4$ & $2.2 \pm 0.4$ & \multirow[t]{2}{*}{0.70} & \multirow[t]{2}{*}{$0.0003 *$} & \multirow[t]{2}{*}{0.43} \\
\hline & NTG & $1.9 \pm 0.4$ & $1.9 \pm 0.4$ & $2.4 \pm 0.8$ & & & \\
\hline
\end{tabular}

Mean CPB time was $107 \pm 42 \mathrm{~min}(97 \pm 32 \mathrm{~min}$ in the control group vs $118 \pm 49 \mathrm{~min}$ in the IV NTG group, $P=0.32$ ).

The mean hemispheric cerebral saturations during $\mathrm{CPB}$ were the same for the NTG and the placebo groups, respectively $58 \pm 7$ vs $56 \pm 11$ (left, $P=0.66$ ) and $55 \pm 6$ vs $49 \pm 12$ (right, $P=0.16$ ). However, the evolution over time of hemispheric cerebral oxygenation during the procedure was different in the IV NTG compared to the placebo group (Table II). In the NTG group, both left and right mean cerebral saturations were unchanged from the beginning to the end of the procedure as compared to the placebo group, in which saturations were significantly lower at the end of $\mathrm{CPB}$ (left side, $P=0.006$; right side, $P=$ 0.005 ). To confirm these results, a post-hoc analysis of the change in cerebral saturation in relation to the baseline value during CBP was performed using data available for the entire CBP. The changes in cerebral saturation as a function of time are shown in Figure 3. The number of episodes with a relative decrease of $20 \%$ or more from the baseline saturation was similar in the IV NTG and the placebo groups: respectively, $1.8 \pm 2.6$ vs $1.5 \pm 1.5$ (left side, $P=0.75$ ), and $1.9 \pm$ 2.6 vs $2.0 \pm 2.3$ (right side, $P=0.89$ ). The proportions of time on $\mathrm{CPB}$ with a saturation below thresh- 

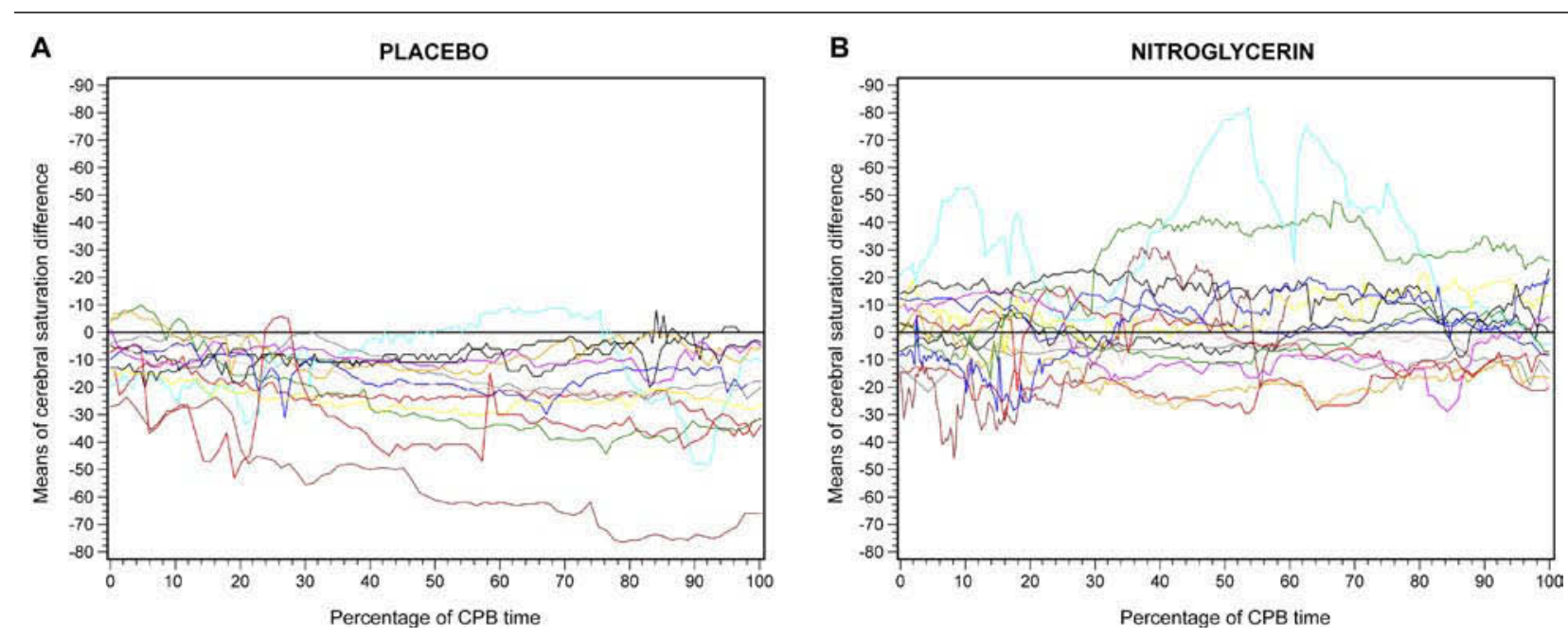

FIGURE 3 Mean cerebral saturation differences during cardiopulmonary bypass (CPB). The mean cerebral saturation difference is the baseline cerebral saturation obtained before CPB minus the real-time value. The duration of CPB is expressed as a percentage of the total duration of $\mathrm{CPB}$. The placebo group values were lower than with nitroglycerin $(P=0.019)$.

TABLE IV Vasopressors and fluids administered

\begin{tabular}{|c|c|c|c|}
\hline & Control & NTG & Pvalue \\
\hline \multicolumn{4}{|l|}{ Vasopressors* } \\
\hline Norepinephrine, $\mu \mathrm{g}$ & $546 \pm 563$ & $1209 \pm 1037$ & 0.04 \\
\hline Norepinephrine, $\mu \mathrm{g} \cdot \min ^{-1} \dagger$ & $2.2 \pm 2.4$ & $4.2 \pm 3.7$ & 0.096 \\
\hline Phenylephrine, $\mu \mathrm{g}$ & $6330 \pm 3931$ & $11,303 \pm 8910$ & 0.06 \\
\hline Phenylephrine, $\mu \mathrm{g} \cdot \mathrm{min}^{-1} \dagger$ & $31 \pm 20$ & $36 \pm 27$ & 0.55 \\
\hline Vasopressin, (U) & $2 \pm 4$ & $3 \pm 4$ & 0.36 \\
\hline Vasopressin, $\left(\mathrm{U} \cdot \mathrm{min}^{-1}\right)$ & $0.0074 \pm 0.0122$ & $0.0116 \pm 0.0137$ & 0.3837 \\
\hline Ephedrine (mg) & $3.5 \pm 7.9$ & $4.3 \pm 8.8$ & 0.78 \\
\hline Ephedrine $\left(\mu \mathrm{g} \cdot \mathrm{min}^{-1}\right)$ & $18.85 \pm 42.93$ & $14.73 \pm 29.59$ & 0.7618 \\
\hline $\begin{array}{l}\text { Intravenous fluids } \\
\text { during surgery }(\mathrm{mL})\end{array}$ & $4972 \pm 1175$ & $5582 \pm 1322$ & 0.19 \\
\hline
\end{tabular}

old were similar for the two groups: left side, $0 \%(0$, 38) vs $14 \%(0,83), P=0.08$; right side, $0 \%(0,75)$ vs $13 \%(0,88), P=0.11$. There was no difference in the baseline value and in the variation of arterial $\mathrm{PCO}_{2}$ over time between groups (Table II). Figure 3 shows the difference in the individual mean left and right saturations minus the baseline saturation profiles over time between the two groups during $\mathrm{CPB}$. The $\mathrm{CPB}$ duration is expressed as a percentage of $\mathrm{CPB}$ time. The mean change in baseline saturation was significantly different between groups (IV NTG: $2.3 \pm 18.7$ vs placebo $-16.7 \pm 14.6, P=0.019)$. The evolution over time of variations of cerebral saturation during $\mathrm{CPB}$ showed no greater decline in the placebo group compared to the IV NTG group $(P=0.06)$.

Both groups maintained similar hemodynamic profiles (Table III) although the right atrial pressures were slightly higher in the NTG group throughout the study (even before the study drug was infused) ( $P$ $=0.03)$, as was the systolic pulmonary artery pressure $(P=0.004)$. When adjusting for the duration of the surgery, the vasopressor requirements between groups were not significantly different (Table IV). No patient in either group had the study drug discontinued as a result of refractory hypotension.

Other clinical outcomes are presented in Table V. Patients in the NTG group had higher CK-MB concentrations the day after surgery (control: $19 \pm 12 \mathrm{U} \cdot \mathrm{L}^{-1}$ ps NTG: $58 \pm 67 \mathrm{U} \cdot \mathrm{L}^{-1}(P=0.006)$. Two deaths occurred in the NTG group. The first patient had a postoperative course complicated by transient renal insufficiency and a cerebrovascular event (diagnosed on postoperative day two). The patient experienced a sudden cardiac arrest on postoperative day 14 , possibly due to a pulmonary embolism. No other cerebrovascular event was observed in either group. A second patient died on postoperative day four. He had severe preoperative left ventricular dysfunction, and experienced a postoperative myocardial infarction. An autopsy revealed global cardiac failure secondary to recent myocardial infarction, without other visible complication. 
TABLE V Other clinical and safety-related outcomes

\begin{tabular}{|c|c|c|c|}
\hline & Control & NTG & P value \\
\hline $\mathrm{CK}-\mathrm{MB} *\left(\mathrm{U} \cdot \mathrm{L}^{-1}\right)$ & $19 \pm 12$ & $58 \pm 67$ & 0.006 \\
\hline Lactates $\left(\mathrm{mEq} \cdot \mathrm{L}^{-1}\right)$ & $1.7 \pm 0.8$ & $2.6 \pm 2.8$ & 0.27 \\
\hline $\begin{array}{l}\text { Post-CPB hemodynamic } \\
\text { instability }(n)\end{array}$ & $10(67)$ & $11(73)$ & 0.69 \\
\hline $\operatorname{IABP}(n)$ & $0(0)$ & $1(7)$ & $\mathrm{N} / \mathrm{A}$ \\
\hline Vasopressors use $>24 \mathrm{hr}(n)$ & $4(27)$ & $8(53)$ & 0.14 \\
\hline ICU stay (days) & $3 \pm 2$ & $5 \pm 4$ & 0.18 \\
\hline Hospital stay (days) & $9 \pm 3$ & $14 \pm 7$ & 0.06 \\
\hline Deaths $(n)$ & $0(0)$ & $2(13)$ & $\mathrm{N} / \mathrm{A}$ \\
\hline \multicolumn{4}{|l|}{ Blood loss ( $m L)$} \\
\hline During surgery & $429 \pm 261$ & $547 \pm 251$ & 0.23 \\
\hline First $24 \mathrm{hr}$ & $460 \pm 304$ & $762 \pm 411$ & 0.03 \\
\hline Heparin (mg) & $306 \pm 118$ & $393 \pm 111$ & 0.047 \\
\hline $\begin{array}{l}\text { Heparin } \\
(\mathrm{mg} / \text { duration of } \mathrm{CPB})\end{array}$ & $3.48 \pm 1.73$ & $3.86 \pm 1.92$ & 0.569 \\
\hline Blood units transfused $(\mathrm{mL})$ & $332 \pm 408$ & $380 \pm 400$ & 0.75 \\
\hline $\mathrm{PaO}_{2} / \mathrm{FIO}_{2}$ ratio & $372 \pm 48$ & $308 \pm 106$ & 0.046 \\
\hline
\end{tabular}

$\mathrm{NTG}=$ nitroglycerin $; \mathrm{CPB}=$ cardiopulmonary bypass; IABP $=$ intra-aortic balloon pump; $\mathrm{CK}=$ creatine kinase; $\mathrm{ICU}=$ intensive care unit; $\mathrm{N} / \mathrm{A}=$ not available because of small number of events; $\mathrm{P} / \mathrm{F}$ ratio $=$ ratio of the partial pressure of oxygen in the arterial blood to inspired fraction of oxygen at the end of surgery. ${ }^{*}$ The CK-MB log value was analyzed because the value did not have a normal distribution.

Table $\mathrm{V}$ also presents safety outcomes. Blood loss was similar in both groups during surgery, but was greater in the NTG group during the first $24 \mathrm{hr}$ after the surgery (control: $460 \pm 304$ vs NTG: $762 \pm 41 \mathrm{l}$ $\mathrm{mL})(P=0.03)$. The $\mathrm{PaO}_{2} / \mathrm{FIO}_{2}$ ratio was lower for patients who received NTG (control: $372 \pm 48 \mathrm{~mL}$ vs NTG: $308 \pm 106 \mathrm{~mL})(P=0.046)$. Intensive care unit mean lengths of stay and hospital lengths of stay (control: $9 \pm 3$ days $v s$ NTG: $14 \pm 7$ days; $P=0.06$ ) were similar in the two groups.

\section{Discussion}

Our results indicate that IV NTG contributes to the maintenance of cerebral oxygen saturation during $\mathrm{CPB}$ for this selected high-risk cardiac surgery population. Although mean cerebral saturations during $\mathrm{CPB}$ were the same in both groups, repeated measures of saturation at specific times of the surgery indicated better preservation of cerebral oxygen saturation in the NTG group at the end of the CPB. Despite a higher pre-CBP cerebral saturation in the placebo group, these patients presented cerebral saturations lower than patients in the IV NTG group at the end of the CBP. These differences are likely attributable to the use of IV NTG, but other explanations need to be considered. Even if many measures were in place to maintain blinding, it is possible that subtle hemodynamic changes at the beginning of the IV NTG infusion might have been detected by the treating anesthesiologist, leading to differences in the management of patients between groups. As cerebral blood flow and cerebral autoregulation can be affected by factors other than cardiac output (such as the $\mathrm{PaCO}_{2}$, $\mathrm{pH}$, and temperature), ${ }^{17}$ variations in any of these parameters during the $\mathrm{CPB}$ might explain, in part, the results given the small sample size.

This study examined the feasibility of the use of an IV NTG infusion during high-risk cardiac surgery, its impact on cerebral saturation, and possible side effects. The sample size neither provided the power to detect differences in neuropsychological or neurological complications, nor to detect differences in any other secondary clinical outcomes. The clinical impact of the detected difference in cerebral saturation is difficult to comment upon. Therefore, although these results suggest a better preservation of cerebral saturation with IV NTG during CPB, we cannot conclude that this will be associated with improved neurological or other clinical outcome. More studies are required to answer these questions.

Previous studies evaluating NIRS in cardiac surgery contribute to our uncertainty regarding the potential benefits of maintaining improved cerebral saturation during cardiac surgery. First, the NIRS technology itself presents several limitations: significant variation in normal inter-individual values, unclear contribution of extracranial blood flow to measurements, and possible unreliability with severe hemodilution. ${ }^{18}$ Second, most of the studies including clinical outcomes had major methodological limitations, such as non-randomized design, and small sample sizes. ${ }^{14}$ Finally, previous studies included strategies to correct desaturations based on previous data, suggesting that prolonged and/or severe desaturations (a decrease of 20-25\% from the baseline cerebral saturation or an absolute value $<50 \%$ ) during cardiac procedures predicts a higher risk of postoperative neuropsychological complications. Intravenous nitroglycerin was rarely part of the treatment protocols in these studies. ${ }^{7,8}$ The four randomized controlled trials currently available showed

B Iglesias IJ, Bainbridge D, Adams S. Monitoring cerebral oxygen saturation significantly decreases postoperative length of stay: a prospective randomized blinded study. Heart Surg Forum 2003; 6: 204.

C Baker RA, Kuring J, Hallsworth L. Prospective randomized evaluation of cerebral oximetry in adult cardiac surgical patients: Clinical and oximetry outcomes. In: Key West Outcomes Meeting; 2005 May 18-21. Key West, FL; 2005.

D Murkin JM, Iglesias I, Bainbridge D. Monitoring cerebral oxygen saturation significantly decreases major organ morbidity in CABG patients: A randomized blinded study. Heart Surg Forum 2004; 7: 515. 
promising outcomes, such as decreased length of hospital stay, ${ }^{\mathrm{B}, \mathrm{C}}$ a lower postoperative stroke rate, ${ }^{\mathrm{D}}$ and reduced major organ dysfunction. ${ }^{15}$ However, none of these studies used IV NTG as part of their strategy to correct episodes of cerebral oxygen desaturation.

Our drug administration protocol has several unique elements. The infusion of IV NTG was started before the ischemic insult of the CPB to prevent a drop in the cerebral saturation during the course of the surgery. The protective effect of IV NTG in ischemia-reperfusion models in animal studies has been explored with promising results. ${ }^{10,11,19,20}$ One of the rare human clinical trials on this topic ${ }^{6}$ evaluated the risk of developing acute respiratory distress syndrome (ARDS) in a group of patients submitted to very high-risk surgeries (estimated risk of ARDS of 10\%). These investigators did not observe any postoperative occurrences of ARDS in their cohort of 56 patients treated with high-dose IV NTG ( $\left.1-5 \mu \mathrm{g} \cdot \mathrm{kg}^{-1} \cdot \mathrm{min}^{-1}\right)$, compared to a $17 \%$ incidence in the control group of 24 patients. The IV NTG group had more favourable transcutaneous oxygen partial pressures as a marker of tissue perfusion. However, this study was not randomized; it incorporated a retrospective cohort comparison group, and used a different measure of peripheral perfusion. The results suggest that maintenance of adequate regional cerebral perfusion can improve patient outcome are intriguing.

The dose of IV NTG used in this study $(0.1 \mu \mathrm{g}$. $\mathrm{kg}^{-1} \cdot \mathrm{min}^{-1}$ ) was based on previous animal and human studies showing a significant therapeutic benefit and on safety studies confirming its tolerability. ${ }^{21,22}$ The absolute amount of vasopressor used in the IV NTG group was greater than in the placebo group, but when corrected for the duration of $\mathrm{CPB}$, the two groups were similar. Hypotension is a frequent occurrence with IV NTG, but when compared to other clinically-used NO donors such as nitroprusside, IV NTG was hemodynamically well tolerated in normovolemic, normotensive patients. ${ }^{23}$

The present study has several limitations. It was powered to detect a difference of $10 \%$ in mean absolute cerebral saturation values. We did not detect this $10 \%$ difference between our groups, but given the higher observed variance in the cerebral saturation than the one used in the sample size calculation, our study was probably underpowered. However, we found a significant difference between groups with the repeated-measures ANOVA, which provides the advantage of using the intra-individual variation of the cerebral saturation over time, increasing the power to detect a difference.

The small number of recruited patients could have compromised the process of randomization, creating two groups with different initial characteristics. The NTG group patients appeared sicker than those of the placebo group. Slightly different baseline characteristics, differences in baseline hemodynamic values, and a concerning difference between total time of $\mathrm{CPB}$ could all indicate an imperfect randomization. In this context, the difference (which did not reach statistical significance) in the baseline cerebral saturations between the two groups is not unexpected.

Other clinical outcomes were concerning. The degree of postoperative CK-MB elevation in the NTG group was greater, even when the patient who died from cardiac failure was excluded. This finding is worrisome, even if its clinical impact is difficult to assess. CK-MB fractionation has been shown to lack specificity for the diagnosis of perioperative myocardial infarction in cardiac surgery. ${ }^{24}$ Our study population included many patients undergoing valvular surgery, for whom precise ischemic cut-offs are even less well defined, ${ }^{25}$ but patients in the NTG group seem to have experienced more perioperative ischemic episodes. The bleeding complications were similar in both groups except for the blood loss during the first $24 \mathrm{hr}$ after the surgery. Previous clinical studies addressing potential increased bleeding complications in cardiac patients receiving both intravenous heparin and IV NTG have never demonstrated more clinical bleeding and transfusion requirement with IV NTG, despite its theoretical antiplatelet effect. ${ }^{26}$ Given the short half-life of IV NTG, the drug was unlikely to have such a prolonged effect in the postoperative period. Nitroglycerin also dilates pulmonary vessels, which can increase intrapulmonary shunt. Accordingly, the partial pressure of oxygen in the arterial blood to inspired fraction of oxygen ratio $\left(\mathrm{PaO}_{2} / \mathrm{FIO}_{2}\right.$ ratio $)$ at the end of surgery was statistically lower in the NTG group. The clinical significance of this between-group difference for $\mathrm{PaO}_{2} / \mathrm{FIO}_{2}$ values over $300 \mathrm{mmHg}$ in both groups is unknown.

In summary, IV NTG infusion before and during $\mathrm{CPB}$ has the potential to maintain cerebral oxygen saturation during $\mathrm{CPB}$ in high-risk patients undergoing complex cardiac surgery. This strategy theoretically offers the advantage of preventing ischemic episodes instead of correcting already established tissue hypoperfusion. However, the clinical benefits of such a strategy require further validation. Further studies are warranted to determine if the potentially harmful effects detected in the present study are real and significant. Larger studies should also define the optimal IV NTG regimen in terms of dose, timing, and mode of administration (continuous $v s$ baseline-rate adjusted in response to changing NIRS values). 


\section{References}

1 Wan S, LeClerc JL, Vincent JL. Inflammatory response to cardiopulmonary bypass: mechanisms involved and possible therapeutic strategies. Chest 1997; 112: 67692.

2 Roach GW, Kanchuger M, Mangano CM, et al. Adverse cerebral outcomes after coronary bypass surgery. Multicenter Study of Perioperative Ischemia Research Group and the Ischemia Research and Education Foundation Investigators. N Engl J Med 1996; 335: 1857-63.

3 Boyle EM, Lille ST, Allaire E, Clowes AW, Verrier ED. Endothelial cell injury in cardiovascular surgery: atherosclerosis. Ann Thorac Surg 1997; 63: 885-94.

4 Sellke FW, Boyle EM, Verrier ED. Endothelial cell injury in cardiovascular surgery: the pathophysiology of vasomotor dysfunction. Ann Thorac Surg 1996; 62: 1222-8.

5 Mebta JL. Endothelium, coronary vasodilation, and organic nitrates. Am Heart J 1995; 129: 382-91.

6 Thangathurai D, Charbonnet C, Wo CC, et al. Intraoperative maintenance of tissue perfusion prevents ARDS. Adult Respiratory Distress Syndrome. New Horiz 1996; 4: 466-74.

7 Goldman S, Sutter F, Ferdinand F, Trace C. Optimizing intraoperative cerebral oxygen delivery using noninvasive cerebral oximetry decreases the incidence of stroke for cardiac surgical patients. Heart Surg Forum 2004; 7: E376-81.

8 Yao FS, Levin SK, Wu D, et al. Maintaining cerebral oxygen saturation during cardiac surgery shortened ICU and hospital stay. Anesth Analg 2001; 92: SCA86 (abstract).

9 Joselevitz-Goldman J, Acad BA, Weiss HR. Effects of nitroglycerin on regional $\mathrm{O} 2$ supply and $\mathrm{O} 2$ consumption in reperfused dog myocardium. Eur J Pharmacol 1989; 166: 283-93.

10 Kawashima M, Bando T, Nakamura T, et al. Cytoprotective effects of nitroglycerin in ischemiareperfusion-induced lung injury. Am J Respir Crit Care Med 2000; 161(3 Pt 1): 935-43.

11 Tang AT, Geraghty P, Dascombe MJ, Jarvis JC, Salmons $S$, Hooper TL. Nitroglycerine reduces neutrophil activation and acute damage in latissimus dorsi muscle grafts. Ann Thorac Surg 1998; 66: 2015-21.

12 Leesar MA, Stoddard MF, Dawn B, Jasti VG, Masden $R$, Bolli R. Delayed preconditioning-mimetic action of nitroglycerin in patients undergoing coronary angioplasty. Circulation 2001; 103: 2935-41.

13 Edmonds HL, Ganzel BL, Austin EH. Cerebral oximetry for cardiac and vascular surgery. Semin Cardiothorac Vasc Anesth 2004; 8: 147-66.

14 Taillefer MC, Denault AY. Cerebral near-infrared spec- troscopy in adult heart surgery: systematic review of its clinical efficacy. Can J Anesth 2005; 52: 79-87.

15 Murkin JM, Adams SJ, Novick RJ, et al. Monitoring brain oxygen saturation during coronary bypass surgery: a randomized, prospective study. Anesth Analg 2007; 104: 51-8.

16 Bernstein AD, Parsonnet V. Bedside estimation of risk as an aid for decision-making in cardiac surgery. Ann Thorac Surg 2000; 69: 823-8.

17 Nollert G, Mohnle P, Tassani-Prell P, Reichart B. Determinants of cerebral oxygenation during cardiac surgery. Circulation 1995; 92: 327-33.

18 Davies LK, Janelle GM. Con: all cardiac surgical patients should not have intraoperative cerebral oxygenation monitoring. J Cardiothorac Vasc Anesth 2006; 20: 450-5.

19 Lefer DJ, Nakanishi K, Johnston WE, Vinten-Johansen $J$. Antineutrophil and myocardial protecting actions of a novel nitric oxide donor after acute myocardial ischemia and reperfusion of dogs. Circulation 1993; 88(5 Pt 1): 2337-50.

20 Bilinska $M$, Maczewski $M$, Beresewicz A. Donors of nitric oxide mimic effects of ischaemic preconditioning on reperfusion induced arrhythmias in isolated rat heart. Mol Cell Biochem 1996; 160-161: 265-71.

21 Bojar RM, Rastegar H, Payne DD, et al.

Methemoglobinemia from intravenous nitroglycerin: a word of caution. Ann Thorac Surg 1987; 43: 332-4.

22 Curry SC, Arnold-Capell P. Toxic effects of drugs used in the ICU. Nitroprusside, nitroglycerin, and angiotensin-converting enzyme inhibitors. Crit Care Clin 1991; 7: 555-81.

23 Sorkin EM, Brogden RN, Romankiewicz JA. Intravenous glyceryl trinitrate (nitroglycerin). A review of its pharmacological properties and therapeutic efficacy. Drugs 1984; 27: 45-80.

24 Bimmel D, Patermann B, Schlosser T, et al. Do we still need $\mathrm{CK}-\mathrm{MB}$ in coronary artery bypass grafting surgery? J Cardiovasc Surg (Torino) 2003; 44: 191-6.

25 Jarvinen A, Mattila T, Kyosola K. Serum CK-MB isoenzyme after aortic and mitral valve replacements. Ann Clin Res 1983; 15: 189-93.

26 Williams H, Langlois PF, Kelly JL. The effect of simultaneous intravenous administration of nitroglycerin and heparin on partial thromboplastin time. Mil Med 1995; 160: 449-52. 